\title{
Surface Integrity of Wire Electrical Discharge Machined Surface of Titanium Alloy
}

\author{
Siva Prasad Arikatla ${ }^{1}$, Dr K.Tamil Mannan ${ }^{2}$, Dr Arkanti Krishnaiah ${ }^{3}$ and Ch.V.Krishna Rao ${ }^{4}$
}

\begin{abstract}
Titanium and its alloys are mostly used in many industries because of its extreme properties. Wire Electrical Discharge Machining (WEDM) has become one of the most popular processes for producing very complex and precise geometries in hard materials like titanium alloy. Improper selection or setting of WEDM process parameters can affect the kerf width, material removal rate (MRR), over cut, surface roughness, surface topography, micro structural changes and metallurgical transformations and totally affect the process performance, efficiency and surface integrity. The surface integrity plays an important role on performance of the wire electrical discharge machined component. This paper presents an experimental investigation on surface integrity of wire electrical discharge machined surface of Titanium alloy. It is observed that the pulse on time, pulse current and servo voltage are mostly influences the kerf width and the MRR increases, as the pulse on time, pulse current, dielectric pressure and servo feed increases. The overcut increases as the pulse on time, pulse current, servo voltage and dielectric pressure increases. The surface roughness increases as the pulse on time, pulse current and servo feed rate increases. From SEM micro graphs it is observed that, at higher pulse on time, pulse current and servo feed rate, the craters and the density of global appendages and pockmarks were high and the thickness of white layer is high at higher values of pulse on time and pulse current. EDX analysis reveals that the carbon percentage increases as the pulse duration and pulse current increases.
\end{abstract}

Keywords - Surface Integrity, Surface Roughness, Titanium alloy, Wire Electrical Discharge Machining.

\section{INTRODUCTION}

Titanium alloys are hard metals which contain a mixture of titanium and other chemical elements. Ti-6Al-4V grade titanium alloy is the most popular and is used for a wide range of applications in the aerospace, marine, power generation and offshore industries. Titanium alloys have very high tensile strength, fatigue resistance, highest strength-to-weight ratio, extraordinary corrosion resistance and toughness at elevated temperatures. However, the high cost of both raw materials and processing has limited the use of titanium alloy to military applications, aero space, aircraft, medical

\footnotetext{
${ }^{1}$ Research Scholar, IGNOU, New Delhi \& Senior Lecturer, DA Govt. Polytechnic, Ongole, 523001, A.P, India.

${ }^{2}$ Associate Professor, School of Engineering \& Technology, IGNOU, New Delhi, 110028, India.

${ }^{3}$ Professor \& Head, Osmania University College of Engineering, Hyderabad, Telangana, India.

${ }^{4}$ Principal, Govt. Model Residential Polytechnic, Gajwel, Medak Dist., Telangana, India
}

devices, connecting rods on expensive sports cars and some premium sports equipment and consumer electronics. The "commercially pure" titanium has acceptable mechanical properties and has been used for orthopedic and dental implants. For most of applications, titanium is alloyed with small amounts of aluminum and vanadium. This mixture has a solid solubility which varies dramatically with temperature, allowing it to undergo precipitation strengthening. This heat treatment process is carried out after the alloy has been worked into its final shape but before it is put into use, allowing much easier fabrication of a high-strength product. Yang, X, Liu, CR et al., has studied the machining of titanium and its alloys [1], Kuriakose, Sh, Shanmugan MS et at., has studied the characteristics of wire electro discharge machined surface of Ti-6Al-4V titanium alloy [2] and Rahman.M.M et al., have done the modeling of machining parameters of Ti-6Al-4V titanium alloy for electrical discharge machining using a neural network approach [3]. Titanium and its alloys are attractive and important materials in modern industry due to their unique properties. Titanium is a very strong and light metal and also incredibly durable and long-lasting, which is used for medical applications. When titanium cages, rods, plates and pins are inserted into the human body, they can last for upwards of 20 years. The non-ferromagnetic property of the titanium is another benefit, which allows patients with titanium implants to be safely examined with MRIs and NMRIs [4]-[5].

Titanium and its alloys are used in many industries such as biomedical applications, automobile, aerospace, chemical field, electronic, gas and food industry [6]. In recent decades, titanium is applied widely in biomedical and medical field because it is absolutely a proper joint with bone and other body tissue, immune from corrosion, strong, flexible and compatible with bone growth. Titanium is used in different medical applications such as dental implants, hip and knee replacement surgeries, external prostheses and surgical instruments [4]-[7]. Elias C.N et al., has studied the bio medical applications of titanium and its alloy [8] and Kumar A et al., has done the investigations into machining characteristics commercially pure titanium using CNC electric discharge machining. On the other hand, there is some limitation for titanium use because of its initial high cost, availability, inherent properties and manufacturability [9]. Machining titanium and its alloys by conventional machining methods has some difficulties such as high cutting temperature and high tool wear ratio. Thus, titanium and its alloys are difficult-to-machine through conventional machining process. Therefore, unconventional machining processes are introduced for machining titanium and its alloys [2]-[6]. Gu.L, Rajukar 
K.P et al., has studied the wire electric discharge machining of Ti-6Al-4V titanium alloy with a bundled electrode [6]. WEDM technology has been widely used in tool and diemaking industry, automotive, medical and practically any conductive materials. It is a non-traditional machining process which used the continuously circulating wire as electrode and cuts the work piece along a programmed path. WEDM known as wire-cut EDM, a thin single-strand metal wire is fed through the work piece submerged in a tank of dielectric fluid. WEDM is typically used to make punches, tools, and dies from hard metals that are difficult to machine with other methods. Wirecutting EDM is commonly used when low residual stresses are desired, because it does not require high cutting forces for removal of material. If the energy per pulse is relatively low, little change in the mechanical properties of a material is expected due to these low residual stresses, although material that has not been stress-relieved can distort in the machining process. The work piece may undergo a significant thermal cycle, its severity depending on the technological parameters used. Such thermal cycles may cause formation of a recast layer on the part and residual tensile stresses on the work piece. Ti-6Al-4V Titanium alloy has become very popular materials and widely used as implants for dental, restorations and orthodontic wires, as well as orthopedic due to their low density, high corrosion resistance and excellent mechanical properties [10]. However these alloys were very difficult to fabricate as they are not ductile and have low fracture toughness at room temperature [11]. Furthermore, due to its excellent strength property, it is found that it is extremely difficult to machine by conventional method. Several researchers [12]-[13] have investigated the different aspects of machining but no comprehensive research work has been reported so far in the field of wire EDM of this alloy. Hence, it is essential to introduce an alternative method in machining of this alloy.

Wire EDM becomes an important non-traditional machining process due to its competency in machining of work pieces with complex geometry and hard stiffness [14]. The material is removed by a series of discrete electrical discharges between the wire electrode and the work piece in this process. The discharges, which are highly focused by the dielectric medium, cause rise in the local temperatures of the work piece near the point of introduction. The temperatures are high enough to melt and vaporize the material in the immediate vicinity of the electrical discharges. Since, there is no mechanical contact between the work piece and the electrode, material of any hardness can be machined as long as it is electrically conductive [15]. Due to this reason, it has dramatically increased in high application of materials with high stiffness in the aerospace, nuclear, and automotive industries. WEDM was effective solutions for machining hard materials such as titanium, molybdenum, zirconium and tungsten carbide with complex shapes and profiles that are difficult to machine using conventional methods [16]-[17]. The improper selection of WEDM parameters causes wire breakage, reduces cutting feed, reduces material removal rate, increases kerf width, over cut, surface roughness, finally which in turn reduces the productivity. The selection of proper cutting parameters is the solution to obtain good surface finish, higher cutting feed and to overcome the drawback in machining. However, even though with the up to- date computer numerical control (CNC) WEDM machines exist, the problem of selecting proper cutting parameters for WEDM processes is not fully solved. Machine feed rate, discharge current, wire speed, wire tension and average working voltage are the machining parameters which affect WEDM performance measures [18]-[19]. The WEDM response variables such as kerf width, MRR, over cut, surface roughness, surface topography, micro structural changes, metallurgical transformations and residual stresses are included in one term called as surface integrity. The surface integrity plays an important role in performance of machined components. This study aimed in achieving the surface integrity of wire electrical discharge machined surface of Ti-6Al-4V titanium alloy at various settings of WEDM process parameters viz. pulse on time or pulse duration, pulse peak current, servo voltage, dielectric fluid pressure, wire feed rate, wire tension and servo feed rate.

\section{EXPERIMENTAL WORK}

The experiments were conducted on ULTRACUT S1 four axis wire cut electrical discharge machine from Electronica India Pvt. Ltd. The titanium alloy of Ti-6Al-4V was used as work piece material for the present investigation. The chemical composition of Ti-6Al-4V titanium alloy by $\%$ weight is given in Table. I. A diffused brass wire of $0.3 \mathrm{~mm}$ diameter was used as the wire electrode due to its extreme properties like electric discharge performance, heat resistance, low calorification and heat release. The chemical composition of brass wire was $63 \%$ copper and $37 \%$ Zinc by weight and its tensile strength is 142000 PSI. Deionized water was used as dielectric fluid because of its low viscosity and rapid cooling rate and its temperature was kept at $20^{\circ} \mathrm{C}$. The process parameters such as pulse on time, pulse peak current, spark gap set voltage, water pressure, wire feed rate, wire tension and servo feed rate has taken at three different levels as shown in Table. II. The experiments were conducted on ULTRACUT S1 Four Axis Wire Cut EDM machine with brass electrode of diameter 0.3 $\mathrm{mm}$ at Central Institute of Tool Design (CITD), Hyderabad, India. The selections of these factors were based on the suggestions from the handbook recommended by the machine manufacturer, preliminary research results and journals. The kerf width was measured with Alltion/Wuzhou Co., Ltd., Model XJL 17 metallurgical optical microscope with sensitivity of $0.01 \mathrm{~mm}$ and magnification of $100 \mathrm{X}$. Ten readings at different ten spots were taken and their average has been considered as kerf width of the cutting slot. The material removal rate was analyzed by taking cutting feed, kerf width and thickness of the test specimen into consideration. Over cut was also determined with the difference of kerf width and wire diameter. The surface roughness was measured with S1500DX/SD2 model SURFCOM with sensitivity of $1 / 2$ Max and at magnification of X10000 along the directions parallel 
and perpendicular to the wire. The surface topography and micro structural changes has been observed with the Hitachi 3400N model Scanning Electron Microscope (SEM) at magnification of X2000. These tests were carried out at School of Engineering Science and Technology, University of Hyderabad, India. The influence of WEDM process parameters such as pulse on time or pulse duration, pulse peak current, servo voltage, wire feed rate, wire tension, dielectric fluid pressure and servo feed rate on response variables such as kerf width, material removal rate, overcut, surface roughness, surface topography, micro structural changes and metallurgical transformations have been studied with reference to the experimental results and these response variables are included in one term called as surface integrity.

TABLE I

CHEMICAL COMPOSITION OF TI-6AL-4V TITANIUM ALLOY

\begin{tabular}{cccccccc}
\hline $\mathrm{C}$ & $\mathrm{Fe}$ & $\mathrm{Al}$ & $\mathrm{O}_{2}$ & $\mathrm{~N}_{2}$ & $\mathrm{~V}$ & $\mathrm{H}_{2}$ & $\mathrm{Ti}$ \\
\hline 0.08 & 0.25 & 5.5 & 0.2 & 0.05 & 3.5 & 0.15 & Balance \\
\hline
\end{tabular}

\begin{tabular}{lccc}
\multicolumn{4}{c}{ TABLE II: TEST CONDITIONS } \\
\hline Process Parameter & L1 & L2 & L3 \\
\hline Pulse on Time $(\mu \mathrm{s})\left(\mathrm{T}_{\text {on }}\right)$ & 100 & 110 & 120 \\
Pulse Peak Current $(\mathrm{IP})$ & 10 & 11 & 12 \\
Servo Voltage $(\mathrm{V})(\mathrm{SV})$ & 40 & 50 & 60 \\
Dielectric Pressure (PSI) (DP) & 5 & 10 & 15 \\
Wire Feed Rate (m/min) (WF) & 5 & 10 & 15 \\
Wire Tension (kgf) (WT) & 1.1 & 1.3 & 1.5 \\
Servo Feed Rate (SF) & 50 & 1050 & 2050 \\
\hline
\end{tabular}

\section{RESULTS AND DISCUSSIONS}

\section{A. Kerf Width}

The kerf width was measured with metallurgical optical microscope with sensitivity of $0.01 \mathrm{~mm}$ and magnification of $100 X$. Ten readings at different ten spots were taken and their average has been considered as kerf width of the cutting slot. The experimental results reveals that, as the pulse on time or pulse duration, pulse peak current, servo voltage, wire feed rate and wire tension increases, the kerf width also increases, as shown in Fig. 1. Pulse on time, pulse peak current and servo voltage are mostly influences the kerf width. The influence of dielectric pressure, wire feed rate, wire tension and servo feed rate are very little on kerf width. Experiment with lower feed rate gives bigger kerf width and as the feed rate increases, the kerf width decreases. Nihat Tosum et al., proved that open circuit voltage and pulse duration are highly affected parameters on both the kerf width and the material removal rate [20]. Aniza Alias et al., is also proved the same [21].

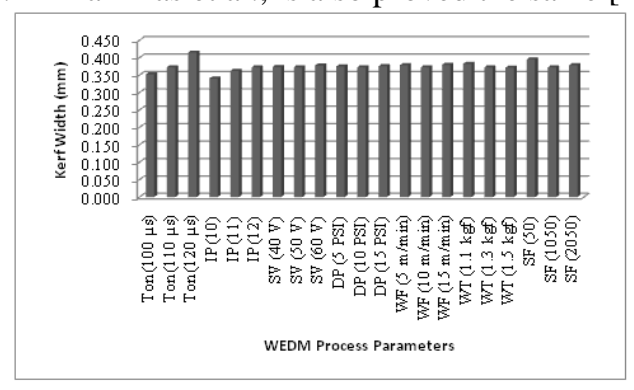

Fig. 1: WEDM Process Parameters vs. Kerf Width

\section{B. Material Removal Rate}

The material removal rate (MRR) was analyzed by taking cutting feed, kerf width and thickness of the test specimen into consideration. The experimental results revels that the MRR increases, as the pulse on time or pulse duration, pulse peak current, dielectric pressure and servo feed rate increases. However, for extended pulse on time or pulse duration and pulse peak current the MRR decreases. Further, it is observed that the MRR decreases as the wire feed rate and wire tension increases, as shown in Fig. 2.

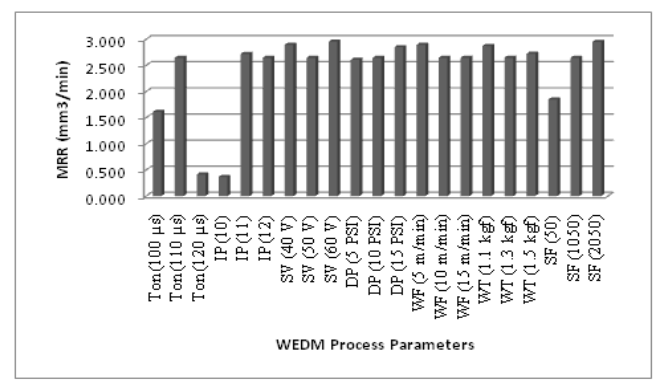

Fig. 2: WEDM Process Parameters vs. MRR

K.P. Somashekhar and Jose Mathew et al., studied the material removal characteristics of micro kerfs geometry in micro wire EDM on aluminum [22]. P.S. Rao et al., predicted the material removal rate in wire cut EDM of BIS 24345 aluminum alloy and used the equation for calculation of MRR as; $\operatorname{MRR}\left(\mathrm{mm}^{3} / \mathrm{min}\right)=\mathbf{F} \times \mathbf{D}_{\mathbf{w}} \mathbf{x} \mathbf{H}$; where ' $\mathrm{F}$ ' is the machine feed rate in $(\mathrm{mm} / \mathrm{min})$, 'Dw, is the wire diameter in $(\mathrm{mm})$ and ' $\mathrm{H}$ ' is the work piece thickness in ( $\mathrm{mm})$ [23]. However, the material removal rate was calculated using the following equation by taking the over cut into consideration as; Material Removal Rate $\left(\mathrm{mm}^{3} / \mathrm{min}\right)=\mathbf{C F} \mathbf{x} \mathbf{K}_{\mathbf{w}} \mathbf{x} \mathbf{t}$; where ' $\mathrm{CF}$ ' is the cutting feed in ( $\mathrm{mm} / \mathrm{min})$, ' $\mathrm{Kw}$ ' is the kerf width in $(\mathrm{mm})$ and ' $t$ ' is the thickness of the work piece in ( $\mathrm{mm})$.

\section{Over Cut}

The reason that the cutting width is greater than the width of the wire is because the sparking occurs from the sides of the wire to the work piece, causing erosion. It is the lateral distance between the wire and work piece during the sparking. The difference between the kerf width and the diameter of wire is considered as 'over cut'. The experimental results reveals that the overcut increases as the pulse on time or pulse duration, pulse peak current, servo voltage and dielectric pressure increases. At higher and lower levels of wire feed and servo feed rate the over cut is more and at moderate wire feed rate and servo feed rate the over cut is low, as shown in Fig. 3. 


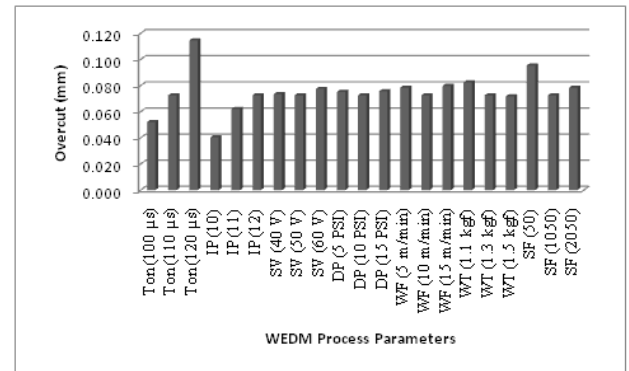

Fig. 3: WEDM Process Parameters vs. Over cut

\section{Surface Roughness and Surface Topography}

The surface roughness was measured with surf tester with sensitivity of $0.001 \mu \mathrm{m}$ along the direction parallel and perpendicular to wire. The experimental results reveals that, as the pulse on time or pulse duration, pulse peak current and servo feed rate increases the surface roughness was also increases. As the servo voltage, dielectric pressure, wire feed rate and wire tension increases, the surface roughness decreases, as shown in Fig. 4. However, for extended servo voltage, dielectric pressure, wire feed rate and wire tension, the surface roughness increases. Servo voltage, dielectric pressure, wire feed rate and wire tension are significant parameters in obtaining the better surface finish. P.S.Rao et al. also proved the same (23).

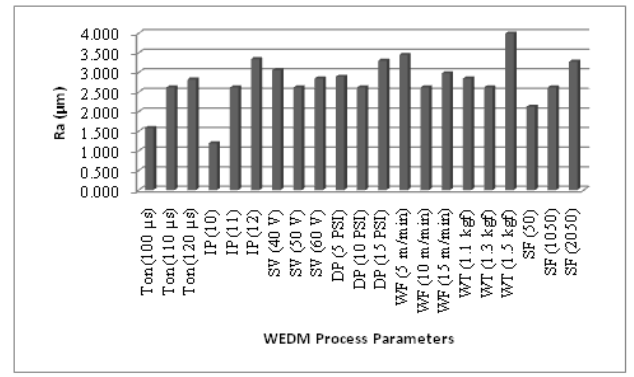

Fig. 4: WEDM Process Parameters vs. Surface Roughness

Surface topography was observed with Hitachi 3400N model SEM at magnification of X2000. The surface roughness, craters and the density of global appendages and pockmarks were reflects the degree of surface topography. From SEM micro graphs it is observed that, at higher pulse on time, pulse peak current and servo feed rate, the craters and the density of global appendages and pockmarks were high, as shown in Fig. 5(a). Further, as the servo voltage, dielectric pressure, wire feed rate and wire tension increases the craters and the density of global appendages and pockmarks were low, as shown in Fig. 5(b). However, for extended servo voltage, dielectric pressure, wire feed rate and wire tension, the craters and the density of global appendages and pockmarks were high.
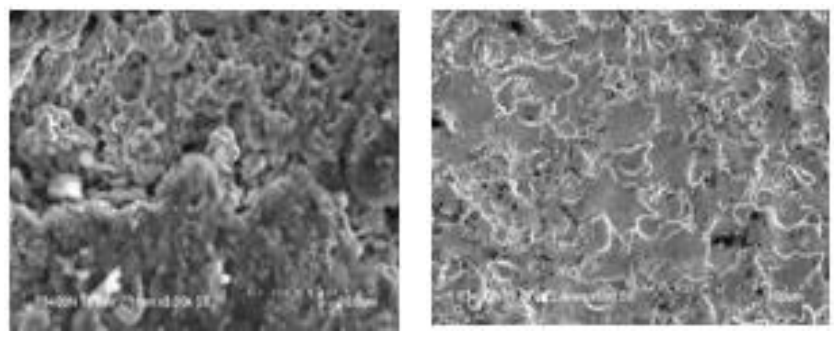

Fig. 5: WEDM Surface at (a) High Pulse on Time and Pulse Current

(b) Low Pulse on Time and Pulse Current

\section{E. Micro Structural Changes and Metallurgical Transformations}

The wire electrical discharge machined surfaces were cleaned with soft brush and etched with $2 \%$ Nital reagents after polishing with $200,400,800$ and zero grade polishing papers and air dried for microstructure observation in the subsurface. Micro structural analysis was carried on a Hitachi $3400 \mathrm{~N}$ model SEM. A white layer, situated at the surface, corresponding to a dentritic phase. It is due to the melting and rapid cooling of the molten metal by the forced circulation of the dielectric fluid during the wire electrical discharge machining process. A quenched or heat affected layer, located directly under the white layer. This layer has a martensitic quenched structure. It depends on the type and hardenability of the titanium alloy and on machining conditions. It is observed that the thickness of white layer is high at higher values of pulse on time or pulse duration and pulse peak current and the thickness of white layer decreases as the pulse duration and pulse peak current decreases, as shown in Fig. 6. Larger pulse on time or pulse duration and pulse peak current allows the high temperature penetrates deeper into the subsurface, which produces more molten material and ultimately results in a thicker white layer.

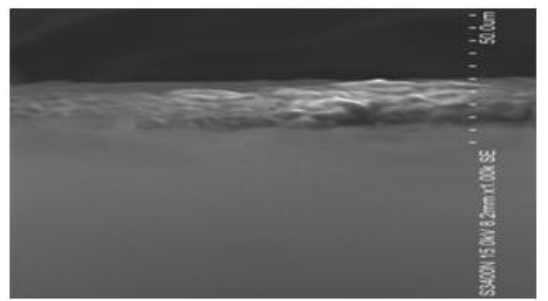

Fig. 6: White Layer on Wire Electrical Discharge Machined Surface

The compositions of the wire electrical discharge machined surfaces were examined by using energy dispersive $\mathrm{x}$-ray (EDX) analysis. There is higher amount of carbon in the craters of the wire electrical discharge machined surfaces. The carbon could possibly come from dielectric fluid due to pyrolysis process. An EDX analysis result reveals that the \% carbon in the wire electrical discharge machined surfaces is high for higher values of pulse on time or pulse duration and pulse peak current and the \% carbon decreases as the pulse on time or pulse duration and pulse peak current decreases, as shown in Fig. 7 (a) \& (b). Further, at higher energy discharge i.e. higher pulse on time or pulse duration and pulse peak current the pyrolysis effect of the dielectric fluid will increase 
which leads to increase the \% of carbon in wire electrical discharge machined surface of titanium alloy.

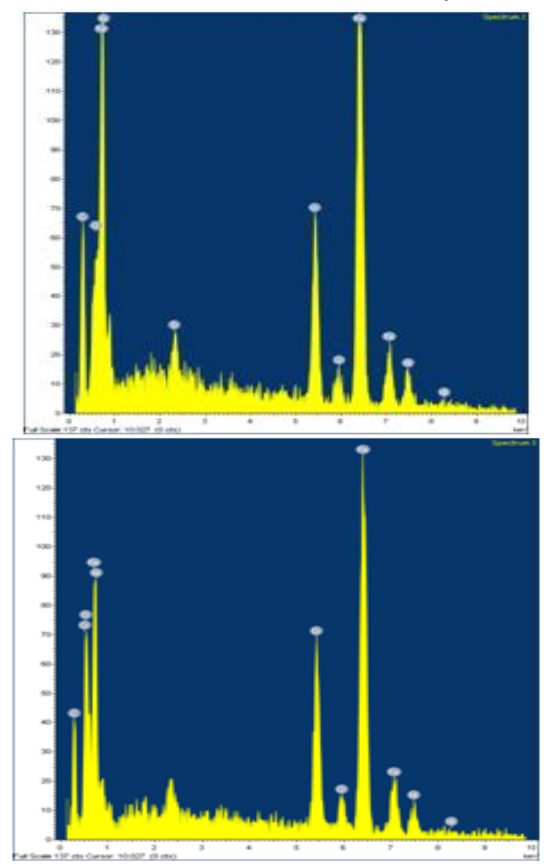

Fig. 7: Increase in \% Carbon at (a) High Pulse on Time and Pulse Current (b) Low Pulse on Time and Pulse Current

\section{CONCLUSIONS}

In this study, the influence of wire EDM parameters such as pulse on time, pulse current, servo voltage, dielectric pressure, wire feed rate, wire tension and servo feed rate on surface integrity of wire electrical discharge machined surface of Titanium alloy has been studied. Based on the experimental results the following conclusions were made:

- It is observed that, as the pulse on time, pulse current, servo voltage, wire feed and wire tension increases, the kerf width also increases. Pulse on time, pulse current and servo voltage are mostly influences the kerf width. The MRR increases, as the pulse on time, pulse current, dielectric pressure and servo feed increases. However, for extended pulse on time and pulse current the MRR decreases. Further, it is observed that the MRR decreases as the wire feed and wire tension increases. The overcut increases as the pulse duration, pulse current, voltage and dielectric pressure increases. At higher and lower values of wire feed and servo feed the over cut is high.

- The experimental results reveals that, as the pulse on time, pulse current and servo feed rate increases the surface roughness was increases. As the servo voltage, dielectric pressure, wire feed and wire tension increases, the surface roughness decreases. From SEM micro graphs it is observed that, at higher pulse on time, pulse current and servo feed rate, the craters and the density of global appendages and pockmarks were high. Further, as the servo voltage, dielectric pressure, wire feed and wire tension increases the craters and the density of global appendages and pockmarks were low. Also observed that the thickness of white layer is high at higher values of pulse on time and pulse current and the thickness of white layer decreases as the pulse duration and pulse current decreases. From EDX analysis, it is observed that the $\%$ carbon in the WEDM surfaces is high for higher values of pulse on time and pulse current and the \% carbon decreases as the pulse on time and pulse current decreases

\section{ACKNOWLEDGMENT}

The authors would like to acknowledge the support from Commissioner of Technical Education, Government of Andhra Pradesh, Central Institute of Tool Design (CITD), Hyderabad, School of Engineering Science and Technology, University of Hyderabad, India, SOET, Indira Gandhi National Open University (IGNOU), New Delhi and all those who supported directly or indirectly are thanked.

\section{REFERENCES}

[1] Yang, X., Liu, C.R., "Machining Titanium and Its Alloys", Machining Science and Technology 3(1), pp. 107-139, 1999. http://dx.doi.org/10.1080/10940349908945686

[2] Kuriakose, Sh., Shunmugam, M.S., "Characteristics of Wire-electro Discharge Machined Ti-6Al-4V Surface", Science Direct (Elsevier) 58, pp. 2231- 2237, 2004.

[3] Rahman, M.M., "Modeling of Machining Parameters of Ti-6Al-4V for Electric Discharge Machining: A Neural Network Approach" Scientific Research and Essays, 7 (8), pp. 881-890, 2012. http://dx.doi.org/10.5897/SRE10.1116

[4] www.tatanium.org, International Titanium Association-Medical Data Sheet, 1999.

[5] Farnaz Nourbakhsh, K. P. Rajurkar, A. P. Malshe, Jian Cao et al., 'Wire electro-discharge machining of titanium alloy' The First CIRP Conference on Biomanufacturing, Procedia, CIRP 5, pp. 13, 2013.

[6] Gu, L., Li,1.,Zhao, W., Rajurkar, K.P., "Electrical Discharge Machining of Ti-6Al-4Vwith a Bundled Electrode", International Journal of Machine Tools and Manufacture, 53 (1), pp. 100-106, 2012. http://dx.doi.org/10.1016/j.ijmachtools.2011.10.002

[7] www.titaniuminfogroup.co.uk, Titanium for Medical Application, $1^{\text {st }}$ August, 2001.

[8] Elias, C.N., Lima, J.H.C.,Valiev, R., Meyers, M.A., "Biomedical Applications of Titanium and its Alloys" Biological Materials Science 60(3), pp. 46-49, 2008. http://dx.doi.org/10.1007/s11837-008-0031-1

[9] Kumar, A., Kumar, V., Kumar, J., "An Investigation into Machining Characteristics Commercially Pure Titanium Using CNC WEDM" Applied Machines and Materials, 159, pp. 56-68, 2012. http://dx.doi.org/10.4028/www.scientific.net/AMM.159.56

[10] P. Kovacs, J. A. Davidson, in: S. A. Brown, J. E. Lemons (Eds.)., "Medical Applications of Titanium and its Alloys" The Materials and Biological Issues, ASTM, pp. 163-178, 1996. http://dx.doi.org/10.1520/STP16077S

[11] B. Pan, D.J. Kim, B.M. Kim, T.A. Dean, "Incremental deformation and the forgeability of titanium aluminide", International Journal of Machine Tools Mfg., 41, pp. 749-759, 2001. http://dx.doi.org/10.1016/S0890-6955(00)00075-4

[12] A.R.C. Sharman, D.K. Aspinwall, R.C. Dewes, D. Clifton, P. Bowen, "The effects of machined work piece surface integrity on the fatigue life of titanium aluminide" , International Journal of Machine Tools and Manufacturing, 41 1681-1685, 2001. http://dx.doi.org/10.1016/S0890-6955(01)00034-7

[13] D.F.Hasson, C.H.Hamilton, Forward, Editors: D. F. Hasson and C. H. Hamilton, "Advanced Processing Methods for Titanium", the Metallurgical Society of AIME, 1982.

[14] K.H. Ho, S.T. Newman, S. Rahimifard, R.D. Allen, "State of the art in wire electrical discharge machining (WEDM)", International Journal of Machine Tools \& Manufacture, 44, pp. 1247-1259, 2004. http://dx.doi.org/10.1016/j.ijmachtools.2004.04.017

[15] D. Rakwal and E. Bamberg, "Slicing, Cleaning and Kerf Analysis of Germanium Wafers Machined by WEDM", Journal of Material Processing Technology, 209(8), pp. 3740-3751, 2009. 
http://dx.doi.org/10.1016/j.jmatprotec.2008.08.027

[16] Sarkar S, Sekh M, Mitra S, Bhattacharyya B.,"Modeling and optimization of wire electrical discharge machining of $\gamma$-TiAl in trim cutting operation", Journal of Material Processing Technology, 205 (13), pp. 376-387, 2008. http://dx.doi.org/10.1016/j.jmatprotec.2007.11.194

[17] Garg RK, Singh KK, Sachdeva A, Sharma VS, Ojha K, Singh S., "Review of research work in sinking EDM and WEDM on metal matrix composite materials", International Journal of Advanced Manufacturing Tech., 50(5-8), pp. 611-624, 2010. http://dx.doi.org/10.1007/s00170-010-2534-5

[18] Gauri SK, Chakraborty S., "A study on the performance of multi response optimization methods for WEDM processes", International Journal of Advanced Mfg. Technology, 49 (1-4), pp. 155-166, 2010. http://dx.doi.org/10.1007/s00170-009-2391-2

[19] Rao RV, Pawar PJ., "Modeling and optimization of process parameters of wire electrical discharge machining", Proc. IME B, Journal of Engineering Manufacturing, 223(11), pp. 1431-1440, 2009. http://dx.doi.org/10.1243/09544054JEM1559

[20] Nihat Tosun, Can Cogun and Gul Tosun, "A study on kerf and material removal rate in wire electrical discharge machining based on Taguchi method", Journal of Materials Processing Technology, Volume 152, Issue 3, pp. 316-322, 2004.

http://dx.doi.org/10.1016/j.jmatprotec.2004.04.373

[21] Aniza Alias, Bulan Abdullah, Norliana Mohd Abbas et al., "Influence of machine feed rate in WEDM of Titanium Ti-6Al-4V with constant current (6A) using brass wire" International Symposium on Robotics and Intelligent Sensors 2012 (IRIS 2012), Procedia Engineering, 41, pp. $1806-1811,2012$. http://dx.doi.org/10.1016/j.proeng.2012.07.387

[22] K.P Somashekhar \& Nottath Ramachandran \& Jose Mathew, "Material removal characteristics of micro slot (kerf) geometry in $\mu$-WEDM on aluminium", International Journal of Advanced Mfg., Tech., 51, pp. 611-626, 2010.

[23] Pujari Srinivasa Rao, Dr. Koona Ramji and Prof. Beela Satyanarayan, "A Prediction of Material removal rate for Aluminum BIS-24345 Alloy in wire-cut EDM", International Journal of Engineering Science and Tech., Vol. 2 (12), 7729-7739, 2010. 